\title{
Indicadores de sustentabilidade em empresas certificadas pela ISO 14.001 do setor de resíduos sólidos
}

\section{Giovanna Cristina de Souza ${ }^{1}$ e Giovano Candiani ${ }^{2}$}

\author{
${ }^{1}$ Universidade Federal de São Paulo. Curso de Graduação em Ciências Ambientais. \\ Campus Diadema. Rua Professor Artur Riedel, 275. Jardim Eldorado. Diadema-SP, \\ Brasil (CEP 09972-270). \\ ${ }^{2}$ Universidade Federal de São Paulo. Departamento de Ciências Ambientais. \\ Campus Diadema. Rua Professor Artur Riedel, 275. Jardim Eldorado. Diadema-SP, \\ Brasil (CEP 09972-270). E-mail: giovanocandiani@gmail.com.
}

Resumo. 0 objetivo do trabalho foi caracterizar os indicadores de sustentabilidade utilizados pelas empresas do setor de resíduos sólidos no Estado de São Paulo, certificadas pela norma ISO 14.001 para monitoramento do desempenho ambiental de seus sistemas de gestão ambiental. 0 método de pesquisa baseou-se em uma revisão sistemática da literatura, pesquisa documental, identificação das empresas certificadas, caracterização e análise dos indicadores de sustentabilidade utilizados por estas empresas. Os principais resultados foram: (i) identificou-se 46 empresas do setor de resíduos sólidos no Estado de São Paulo, sendo que 23 empresas (50\%) são certificadas e destas, 15 (65\%) apresentam a certificação pela norma ISO 14.001, (ii) as empresas SOLVÍ e ESTRE se destacam pelo número de certificações e são as únicas, que apresentam relatórios de sustentabilidade, permitindo verificar o uso dos indicadores de sustentabilidade e (iii) verificou-se que alguns indicadores de sustentabilidade utilizados por estas empresas, constam da Metodologia GRI (Global Reporting Initiative), podendo servir de base para as discussões iniciais, em relação ao uso dos indicadores de sustentabilidade nas empresas do setor de resíduos sólidos, porém ainda existem muitos desafios para a implantação de sistemas de avaliação de desempenho ambiental e de sustentabilidade nas empresas do setor.

Palavras-chave: Sistema de gestão ambiental; Certificação ISO 14.001; Indicadores de sustentabilidade; Resíduos sólidos.

Abstract. Sustainability indicators in companies certified by ISO 14.001 of the solid waste sector. The objective of this study was to characterize the sustainability indicators used by companies in the solid waste sector in the State of São Paulo, certified by ISO 14.001 to monitor the environmental performance of their environmental management systems. The research method was based on a systematic review of literature,
Recebido

$17 / 10 / 2020$

Aceito

$30 / 12 / 2020$

Disponível on line $31 / 12 / 2020$

Publicado

$30 / 04 / 2021$

Acesso aberto

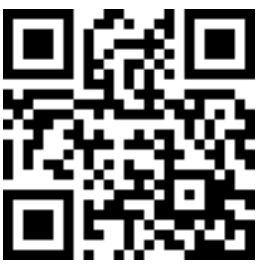

ORCID

(D) 0000-0001-9811-3895 Giovanna Cristina de Souza

D) 0000-0001-9896-4390 Giovano Candiani

ISSN 2359-1412/RBGAS-2020-0178/2021/8/18/1/3

Rev. Bras. Gest. Amb. Sustent.

http://revista.ecogestaobrasil.net 
documental research, identification of certified companies, characterization and analysis of the sustainability indicators used by these companies. The main results were: (i) 46 companies from the solid waste sector in the State of São Paulo were identified, of which $23(50 \%)$ are certified and $15(65 \%)$ are certified by ISO 14.001, (ii) the companies SOLVÍ and ESTRE stand out by the number of certifications and are the only ones that present sustainability reports, allowing to verify the use of sustainability indicators and (iii) it was verified that some sustainability indicators used by these companies are included in the GRI (Global Reporting Initiative) Methodology, and may serve as a basis for the initial discussions regarding the use of sustainability indicators for companies in the solid waste sector, but still there are many challenges for the implementation of environmental performance and sustainability assessment systems in companies in the sector.

Keywords: Environmental management system; ISO 14001 certification; Sustainability indicators; Solid waste.

\section{Introdução}

As empresas passaram a se adaptar às novas exigências do mercado, provocadas pela busca crescente do desenvolvimento sustentável e pressões em relação às questões ambientais por parte dos órgãos ambientais e sociedade como um todo (Damian, 2015). Por outro lado, as abordagens para a gestão ambiental, tratando as questões ambientais pela inserção do controle ou prevenção da poluição ou ainda incorporação desses problemas ambientais nas estratégias das empresas, representam aos seus sistemas produtivos e de serviços, ganhos financeiros e aumento de competitividade, em resposta à demanda de um mercado consumidor cada vez mais exigente (Barbieri, 2011).

Nesse sentido, as organizações buscam a implementação de sistemas de gestão ambiental, através de estratégias administrativas e operacionais inter-relacionadas, prevenindo o surgimento dos problemas ambientais. Barbieri (2011, p. 147) define a necessidade de uma abordagem sistêmica da gestão ambiental em relação à organização e uniformização de ações e procedimentos frente ao objetivo da conservação ambiental. As organizações optam pela implantação da Norma ISO 14.001:2004 referente ao sistema de gestão ambiental. Esta norma exige a utilização de indicadores de sustentabilidade, que possam avaliar a condição ambiental dos processos em uma organização e, consequentemente seu desempenho ambiental.

Muitas empresas do setor de resíduos sólidos, estão implantando sistemas de gestão ambiental, atendendo as exigências ambientais e, desta maneira, aperfeiçoando sua prestação de serviço referente ao gerenciamento adequado de resíduos sólidos, que envolve as seguintes atividades: coleta, segregação, transporte, tratamento e disposição final.

Assim, este trabalho buscou caracterizar os indicadores de sustentabilidade utilizados pelas empresas do setor de resíduos sólidos no estado de São Paulo, certificadas pela Norma ISO 14.001:2004 para o monitoramento do desempenho ambiental de seus sistemas de gestão ambiental.

A implantação da gestão ambiental é uma das melhores formas para se obter melhorias de desempenho ambiental em uma empresa. As organizações compreenderam que somente melhorias técnicas não levam mais a excelência e competitividade no 
mercado, pois apenas vender o produto ou serviço não está mais garantindo a perpetuidade dos negócios. Neste contexto, cresce a exigência do mercado consumidor e a concepção legal de responsabilidade das empresas sobre seus impactos das mais variadas naturezas ambiental, social e econômica (Morioka e Carvalho, 2017). Diante dos diversos problemas, com magnitude crescente as organizações precisavam avançar e assim atualmente observa-se que estas se preocupam cada vez mais e buscam satisfazer suas partes interessadas. Daí a importância da implantação da gestão ambiental e adoção de ferramentas que internalizem as questões ambientais na rotina corporativa (Damian, 2015). As organizações, ao saírem de uma atitude tipicamente reativa, sobretudo em relação ao meio ambiente, partiram nas últimas décadas para atitudes mais proativas, priorizando a prevenção, o controle e a melhoria contínua. Isso só se dá de forma mais eficaz quando essas atitudes passam a integrar a rotina gerencial da organização, na forma de um sistema de gestão (Abrantes, 2009; Barbieri, 2011). Este sistema de gestão na atualidade representa de certo modo um sistema unificado, ou seja, integrado.

Os sistemas de gestão integrados (SGI) permitem integrar os processos de qualidade (norma ISO 9001), gestão ambiental (ISO 14001), segurança e saúde (antiga OHSAS 18001, atual ISO 45001) e responsabilidade social (SA 8000 e ISO 26000).

Estes sistemas de gestão apresentam elementos estruturais comuns, começando com uma política que deve ser desenvolvida e promovida pela alta direção. Tal política estabelece o requisito de definição das políticas da qualidade, meio ambiente, saúde e segurança e responsabilidade social. Em seguida, a organização deve estabelecer os objetivos e metas de seus planos de gestão, incluindo o item planejamento, bem como sua implementação e operação. Também é necessário definir o monitoramento do plano de gestão, medindo-se a obtenção das metas, ações preventivas e corretivas dos sistemas e finalmente, à análise crítica do sistema, apoiado por meio de um processo de auditoria. A similaridade existente entre a implementação destas diferentes normas e o crescente uso destas normas pelas organizações, favorece as discussões em prol da unificação desses processos (Ribeiro Neto et al. 2017).

\section{Metodologia}

Realizou-se esse estudo, a partir da identificação das empresas do setor de resíduos sólidos certificadas pela Norma ISO 14.001:2004, verificação dos indicadores de sustentabilidade utilizados por estas empresas e análise do uso dos indicadores de sustentabilidade no desempenho ambiental dessas empresas.

Esta pesquisa se trata de um estudo descritivo e exploratório por ter como objetivo principal, o aprimoramento de ideias e descoberta de instituições (Gil, 2007). Objetivandose primeiramente identificar as empresas certificadas do setor de resíduos sólidos. Em seguida, verificam-se os indicadores utilizados por estas instituições e por fim elabora-se uma análise geral destes indicadores com base nos seguintes documentos: ABNT NBR ISO 14.001:2015 (sistema de gestão ambiental), ABNT NBR ISO 14.001:2004 (desempenho ambiental) e Diretrizes para Relato de Sustentabilidade - Global Reporting Initiative (GRI, 2013).

A pesquisa inclui ainda: levantamento bibliográfico e documental. A delimitação da pesquisa em relação ao Estado de São Paulo, é em função de que este representa uma parcela muito significa do número de certificações válidas no Brasil. A escolha das empresas certificadas do setor de resíduos sólidos, justifica-se pelo fato de que a certificação nesse ramo de atividade ainda é bem recente e, portanto, as empresas estão buscando suas certificações e aprimorando o uso de indicadores ambientais de desempenho ambiental, representando desta maneira um cenário interessante para análise.

Rev. Bras. Gest. Amb. Sustent., 2021, vol. 8, n. 18, p. 3-19. 
A obtenção de dados para esta pesquisa ocorreu por meio das seguintes etapas/procedimentos: levantamento bibliográfico, identificação das empresas certificadas do setor de resíduos sólidos no estado de São Paulo, caracterização dos indicadores ambientais utilizados por estas empresas, pesquisa documental e análise destes indicadores ambientais.

O levantamento bibliográfico foi realizado em publicações científicas, pesquisandose: livros, trabalhos de conclusão de curso, dissertações e teses e em bases indexadas digitais: "periódicos Capes", "teses e dissertações USP" e "Scielo". A busca foi feita pelo título (palavras-chave) com: "indicadores ambientais", "certificação", "ISO" e "desempenho ambiental". A identificação das empresas do setor de resíduos sólidos certificadas foi obtida por meio de consultas nas seguintes instituições listadas na Tabela 1.

Tabela 1. Instituições certificadoras do setor de resíduos sólidos consultadas.

\begin{tabular}{|l|c|l|}
\hline Instituição & Sigla & \multicolumn{1}{|c|}{ Portal } \\
\hline $\begin{array}{l}\text { Instituto Nacional de Metrologia, } \\
\text { Qualidade e Tecnologia, }\end{array}$ & INMETRO & $\begin{array}{l}\text { http://certifiq.inmetro.gov.br/Consulta } \\
\text { /ConsultaEmpresas }\end{array}$ \\
\hline Associação Brasileira de Normas Técnicas & ABNT & $\begin{array}{l}\text { http://www.abnt.org.br/certificacao/b } \\
\text { usca-de-empresa-certificada }\end{array}$ \\
\hline $\begin{array}{l}\text { Associação Brasileira de Empresas de } \\
\text { Limpeza Pública e Resíduos Especiais }\end{array}$ & ABRELPE & http://www.abrelpe.org.br \\
\hline $\begin{array}{l}\text { Associação Brasileira de Empresas } \\
\text { Tratamento de Resíduos e Efluentes }\end{array}$ & ABETRE & http://www.abetre.org.br \\
\hline Associação Brasileira Resíduos Sólidos & ABLP & http://www.ablp.org.br \\
\hline Autoridade Municipal de Limpeza Urbana & AMLURB & $\begin{array}{l}\text { http://www.prefeitura.sp.gov.br/cidad } \\
\text { e/secretarias/inovacao/amlurb }\end{array}$ \\
\hline $\begin{array}{l}\text { Sindicato dos Trabalhadores em } \\
\text { Empresas de Prestação de Serviços de } \\
\text { Asseio e Conservação e Limpeza Urbana } \\
\text { de São Paulo }\end{array}$ & SIEMACO & http://www.siemaco.com.br \\
\hline
\end{tabular}

O levantamento documental foi realizado na internet, através da ferramenta Google, utilizando-se as seguintes expressões: "ISO 14.001", "ISO 14.031", "Balanço Social", "Relatório de Sustentabilidade" e "Relatório Socioambiental" e acessos aos sites das empresas e contatos via e-mail e telefônico. A análise dos indicadores ambientais deu-se por meio da leitura e avaliação dos seguintes documentos: Norma ABNT NBR ISO 14.001: 2015, Norma ABNT NBR ISO 14.031:2004, Diretrizes para Relato de Sustentabilidade Global Reporting Initiative - GRI (2013), Indicadores Instituto Ethos (2015) e Balanços Sociais, Socioambientais e de Sustentabilidade das empresas.

\section{Resultados e discussão}

\section{Panorama das empresas do setor de resíduos sólidos e suas certificações}

Foram identificadas 46 empresas do setor de resíduos sólidos no estado de São Paulo. As empresas do setor de resíduos sólidos prestam serviços ambientais a prefeituras e empresas de distintos setores produtivos. Estes serviços são relacionados ao gerenciamento de resíduos sólidos urbanos e industriais, incluindo varrições, coletas, galpões de transbordo, operações em aterros sanitários, usinas de coleta seletiva e reciclagem, sistemas de compostagem, incinerador, plantas de coprocessamento de 
resíduos, unidades de tratamento de serviços de saúde e termelétricas. Destas 46 empresas, 23 (50\%) são certificadas.

As seguintes normas foram registradas: ISO 9.001 (qualidade), ISO 14.001 (meio ambiente), OHSAS 18.001, atual ISO 45.001 (segurança no trabalho e saúde ocupacional), SA 26.000 (responsabilidade social) e ISO 37.001 (gestão antissuborno).

A maioria destas empresas é certificada pela Norma ISO 9.001 e 14.001, certificações já consolidadas no âmbito empresarial, diferentemente das outras normas mencionadas, que são mais recentes e exigem mais quanto à implantação, demandando maiores investimentos e cuidados por parte da organização na gestão de seus processos como um todo. Das 23 empresas certificadas, 15 (65\%) apresentam a certificação pela norma ISO 14.001. Em termos de certificações, destaca-se o Grupo ESTRE, que é constituído pelas empresas Cavo, Resicontrol, Oxil e Viva Ambiental, apresentando as seguintes certificações: ISO 9.001, ISO 14.001, ISO 45.001 e ISO 37.001 e o Grupo SOLVÍ, representado pelas empresas GRI, Koleta Ambiental, Organosolví e Essencis, que apresentam as seguintes certificações: ISO 9.001, ISO 14.001 e ISO 45.001. Somente uma empresa, a Renova Ambiental apresenta as 5 certificações, fato bastante significativo, mostrando um elevado grau de maturidade dessa organização frente a gestão empresarial e, sobretudo excelência gerencial.

Barbieri (2011) salienta que um sistema de gestão é um conjunto de atividades administrativas e operacionais, que se interagem para solucionar ou prevenir problemas em geral nos processos de uma determinada organização. O Sistema de Gestão Integrado (SGI), caracteriza-se por um sistema em que a organização engloba aspectos de qualidade (Sistema de Gestão da Qualidade, SGQ), meio ambiente (Sistema de Gestão Ambiental, SGA), segurança do trabalho e saúde ocupacional (Sistema de Gestão Segurança e Saúde Ocupacional, SGSSO) e responsabilidade social - Sistema de Gestão de Responsabilidade Social, SGRS (Barbieri, 2011; Nogueira e Capaz, 2014).

Quando se fala em Sistema de Gestão é fundamental estabelecer ações que possam controlar, monitorar e melhorar processos como um todo, principalmente em relação ao comprometimento com a melhoria contínua e excelência. Este aprimoramento geral, sumariamente representado pela melhoria de desempenho, geralmente se baseia na aplicação do Ciclo PDCA - Plan: planejar, Do: executar, Ckeck: checar e Act: ajustar. 0 ciclo baseia-se na premissa de sua aplicação, ou seja, passos necessários para aperfeiçoar o desempenho de um processo qualquer (Abrantes, 2009).

Uma entidade mundialmente conhecida é a Organização Internacional para Padronização, a ISO - Internacional Organization for Standardization. Sediada em Genebra na Suíça e composta por representantes de diversos países que discutem, elaboram e publicam normas internacionais em várias áreas. No Brasil, a ISO é representada pela Associação Brasileira de Normas Técnicas (ABNT), daí a existência da sigla NBR (Norma Brasileira) precedendo as publicações das normas brasileiras (Barbieri, 2011). Além da ISO, outras entidades também elaboram normas, como: a OHSAS - Occupational Health and Safety Assessment Series, ou seja, Série de Avaliação da Segurança e Saúde no Trabalho e a SA - Social Accountability (Responsabilidade Social) criada pela Organização não governamental SAI (Social Accountability International) sediada nos Estados Unidos (Nogueira \& Capaz, 2014).

A versão da norma de qualidade em uso é a ABNT NBR ISO 9.001:2015. No ano de 2018 foram reportadas aproximadamente 1.106 .356 certificações já emitidas no mundo (SGS, 2019). No Brasil atualmente existem 5.791 certificados válidos (INMETRO, 2019).

A versão vigente da norma de gestão ambiental é a ABNT NBR ISO 14.001:2015. Em 2018 consta um total de cerca de 346.187 certificados emitidos no mundo (BANAS, 2019). No Brasil existem 742 certificados válidos (INMETRO, 2019). 0 Estado de São Paulo se destaca com 371 certificados (INMETRO, 2019). Como tendência geral é possível 
observar um aumento crescente ao longo dos anos em relação ao número de certificações emitidas mundialmente (BANAS, 2019; INMETRO, 2019).

Em relação a gestão de saúde e segurança do trabalho - norma OHSAS 18.001, a versão vigente até 2018 foi a OHSAS 18.001:2007, entretanto em 2019 esta norma foi desabilitada e substituída pela norma ABNT NBR ISO 45.001:2018 (ABNT, 2019). Quanto ao sistema de gestão de responsabilidade social - normas ISO 26.000 e SA 8.000, o Brasil se destaca neste requisito e em 2012 editou a ABNT NBR 16.001:2012, sendo aplicável somente em nosso país (INMETRO, 2019).

\section{Relatórios de sustentabilidade e os indicadores}

Somente os Grupos ESTRE e SOLVÍ apresentam Relatórios de Sustentabilidade, permitindo verificar os indicadores de sustentabilidade utilizados por estas empresas. Estes documentos estão prontamente disponíveis nos sites dessas empresas. Portanto, foi possível de fato confirmar o uso de indicadores de sustentabilidade, somente com as empresas destes Grupos. Contatando as outras empresas certificadas, elas comentam que apresentam indicadores de sustentabilidade, mas que estes não se encontram disponíveis para consultas. Algumas dessas empresas, disseram para formalizar um pedido solicitando acesso aos indicadores, pois o uso deles é tratado no âmbito da gestão da empresa e, portanto, não ficam disponíveis à sociedade. Em alguns casos formalizamos as solicitações, entretanto não obtivemos as informações.

Os Grupos ESTRE e SOLVÍ publicam regularmente ano a ano seus Relatórios Ambientais, fato que facilita muito o levantamento e análise dos indicadores utilizados por estas empresas. O Grupo Solví publicou seu Relatório Anual - 2018 de forma conjunta incluindo todas as suas empresas. Os indicadores são divididos em quatro pilares: institucional, ambiental, social e econômico. A SOLVí atua como unidades de valorização sustentável com atividades no tratamento e destinação de resíduos, saneamento básico, energia e projetos de engenharia ambiental. Esta se divide em quatro subgrupos: Solví Resíduos Públicos, com empresas como LOGA, INOVA e VEGA, Solví Soluções Industriais (Essencis, GRI, Organosolví e Koleta Ambiental), Solví Valorização Energética (Biotérmica Energia e Termoverde) e Solví Saneamento. Todas estas empresas atuam em 89 unidades operacionais, incluindo aterros sanitários, usinas de triagem, plantas de compostagem, unidades de tratamento de resíduos de saúde etc. (SOLVÍ, 2018).

O Grupo ESTRE publicou seu último Relatório de Sustentabilidade - 2017, o documento inclui dados de desempenho sociambiental, econômico, operacional e de relacionamento com a sociedade. 0 relatório é orientado pela metodologia internacional Relato GRI (Global Reporting Initiative). Também reforça o compromisso de contribuir com os Objetivos Globais para o Desenvolvimento Sustentável da Organização das Nações Unidas (ONU) - Agenda 2030. O relatório foi elaborado por meio de consultas as partes interessadas (Stakeholders), sendo a base para construção da matriz de materialidade. A matriz é elaborada através do cruzamento dos temas estratégicos da organização, com os assuntos prioritários para seus públicos de interesse. Com base nestas discussões foram definidos sete temas prioritários: impacto social nas comunidades do entrono dos aterros sanitários, inovação e tecnologia na gestão de resíduos, saúde e segurança, ecoeficiência, educação ambiental, governança, transparência e ética e qualidade e eficiência na operação (ESTRE, 2017).

O Grupo ESTRE é constituído pelas empresas: Cavo, Oxil, Viva Ambiental e Resicontrol. Estas atuam em distintos processos operacionais, como: aterros, transbordo, unidades de reciclagem, coleta/limpeza pública, central de biogás, estação de tratamento de efluente e coprocessamento. Em relação aos indicadores, destaca-se que o Grupo Solví apresenta indicadores de sustentabilidade específicos de quatro empresas: GRI, Koleta Ambiental, Organosolví e Essencis. Entretanto, o Grupo ESTRE apresenta indicadores de sustentabilidade gerais, portanto não associa estes a uma determinada empresa do grupo. 
Aspecto que inviabiliza a determinação de quantas empresas do grupo apresentam indicadores ambientais de fato.

Porém, considerando as empresas do Grupo SOLVÍ, que efetivamente apresentam seus indicadores no Relatório de Sustentabilidade e que o Grupo ESTRE é constituído por 4 empresas e na hipótese de que todas estas empresas deste Grupo contribuem com os indicadores de sustentabilidade, têm-se um total de pelo menos 8 empresas do setor de resíduos sólidos, que possuem indicadores de sustentabilidade. Considerando o total de empresas certificadas (23), teríamos aproximadamente 35\% (8 empresas) do setor de resíduos sólidos no estado de São Paulo utilizando indicadores de sustentabilidade, no monitoramento de seus processos produtivos. Neste contexto, trabalharemos a partir de agora, a análise dos indicadores de sustentabilidade das empresas SOLVÍ e ESTRE.

Os indicadores de sustentabilidade destas empresas são estruturados em pilares, constituídos por: indicadores institucional, ambiental, social e econômico. Em termos institucionais as empresas apresentam suas missões, visões, valores e princípios de gestão (Tabela 2). Nota-se a incorporação por parte destas organizações de valores culturais significativos no contexto socioambiental, destacando-se elementos fundamentais, como: respeito ao meio ambiente, crescimento sustentável, responsabilidade socioambiental e ainda a incorporação dos códigos de condutas, com preceitos de leis anticorrupção empresarial, inclusive de canais de comunicação e conduta ética, com a implantação da norma ABNT ISO 37.001 para gerenciamento antissuborno e política de conflito de interesses (ESTRE, 2017).

Tabela 2. Cultura de valores das empresas SOLVÍ e ESTRE.

\begin{tabular}{|l|l|l|}
\hline \multirow{2}{*}{ Pilar Institucional } & \multicolumn{1}{|c|}{ Grupo SOLVí } & \multicolumn{1}{|c|}{ Grupo ESTRE } \\
\cline { 2 - 3 } & $\begin{array}{l}\text { Oferecer soluções em resíduos, } \\
\text { saneamento, valorização energética } \\
\text { e engenharia, operando e } \\
\text { Missão } \\
\text { paranciando concessões e contratos }\end{array}$ & $\begin{array}{l}\text { Prover soluçóes ambientais } \\
\text { inovadoras de forma segura, } \\
\text { responsável e ética para melhorar a } \\
\text { qualidade de vida da sociedade, } \\
\text { promovendo sua conscientização e } \\
\text { engajamento, gerando valor aos } \\
\text { clientes e acionistas. }\end{array}$ \\
\hline Visão & $\begin{array}{l}\text { Ser o melhor grupo de empresas de } \\
\text { gestão em engenharia de soluções } \\
\text { para a vida e referência na oferta de } \\
\text { serviços diferenciados, integrados e } \\
\text { inovadores. }\end{array}$ & $\begin{array}{l}\text { Liderar e ser referência no mercado } \\
\text { brasileiro de soluções ambientais } \\
\text { de forma inovadora, ética e } \\
\text { sustentável. }\end{array}$ \\
\hline Valores & $\begin{array}{l}\text { Integridade, dinamismo, equipe, } \\
\text { excelência, inovação, } \\
\text { responsabilidade socioambiental e } \\
\text { parceria. }\end{array}$ & $\begin{array}{l}\text { Reconhecemos e valorizamos nossa } \\
\text { gente, fazemos o certo, com } \\
\text { segurança, temos paixão pelo } \\
\text { negócio, agimos como dono, } \\
\text { atuamos com humanidade, } \\
\text { simplicidade e ética e estimulamos } \\
\text { a inovação. }\end{array}$ \\
\hline Princípios de gestão & $\begin{array}{l}\text { Harmonizar as expectativas dos } \\
\text { clientes e usuários com a busca de } \\
\text { resultados empresariais. }\end{array}$ & $\begin{array}{l}\text { Fortalecimento da reputação } \\
\text { institucional e públicos de interesse. } \\
\text { Cultura de Sustentabilidade. Gestão } \\
\text { Ambiental e Inovação em gestão de } \\
\text { resíduos. }\end{array}$ \\
\hline
\end{tabular}

Fonte: Elaborado a partir do Relatório Socioambiental SOLVí (2018) e Relatório de Sustentabilidade ESTRE (2017). 
É cada vez mais frequente o uso de ferramentas, que expressam de certo modo o comportamento organizacional de uma organização, incluindo questões ambientais e de sustentabilidade, sociais e econômicas. Neste contexto, a utilização de indicadores é de fundamental importância. 0 termo indicador é originário do latim indicare, que significa descobrir, apontar, anunciar ou estimar. Os indicadores podem comunicar ou informar sobre o progresso em direção a uma determinada meta (Van Bellen, 2004; Van Bellen, 2006; Santiago e Dias, 2012). Os indicadores de sustentabilidade não são apenas medidas de impacto sobre o meio ambiente, mas podem também ser expressões que contenham informações sobre condições ambientais. Os indicadores de desempenho ambiental apontam medidas de evolução em direção à sustentabilidade (Takashina, 1999; Pereira et al. 2014).

Souza et al. (2017) relatam que indicadores resumem informações de um processo/atividade, demonstrando de forma objetiva o seu desempenho, podendo ser quantitativo ou qualitativo. Tais indicadores baseiam-se em questões de ordem operacional-financeira, entretanto, vem crescendo o uso de indicadores de sustentabilidade, principalmente para avaliar potenciais oportunidades ou riscos de uma atividade/organização e compreender claramente quais variáveis podem potencialmente influenciar um resultado planejado ou seu desempenho esperado.

Os indicadores de sustentabilidade são organizados basicamente em quatro dimensões (Pereira et al., 2014; Campos et al., 2013): social (necessidades humanas, qualidade de vida e justiça social), ambiental (uso dos recursos naturais e degradação ambiental), econômica (desempenho econômico e financeiro) e institucional (orientação política, capacidade e esforço governamental). Classicamente as metodologias disponíveis na literatura, orientam o uso de indicadores em três esferas da sustentabilidade: econômica, ambiental e social (Van Bellen, 2006; Barbieri, 2011). Ainda em relação ao conjunto de indicadores de sustentabilidade, várias instituições (FIESP, 2004; IBGE, 2004; FIRJAN, 2008; GRI, 2013; PNIA, 2012; Instituto Ethos, 2015) e pesquisadores (Wackernagel e Rees, 1996; Souza et al., 2009; Sánchez, 2013; Dongab e Hauschilda, 2017) apresentam sugestões, incluindo temas, como: matéria-prima, água, energia, resíduos, uso e ocupação do solo e biodiversidade.

Uma organização divulga seu desempenho por meio de relatórios de sustentabilidade e/ou balanço social, que objetivam deixar transparente a responsabilidade socioambiental da empresa. A ênfase na transparência de todo o processo de comunicação é o ponto central de um novo entendimento sobre a responsabilidade social afinada com o movimento do desenvolvimento sustentável (Barbieri, 2011). Um texto claro, assertivo, com compromissos reais e factíveis em conjunto com os indicadores determinados, amadurece a análise crítica e estreita relações de uma organização com seus clientes, acionistas, fornecedores, sociedade ou outras partes interessadas (Fogliatti, 2011; Nogueira e Capaz, 2014).

Uma referência muito utilizada é a da organização Iniciativa de Reporte Global, GRI (Global Reporting Initiative), que se refere a um conjunto de indicadores de sustentabilidade de desempenho econômico, ambiental e social (GRI, 2013). Os indicadores do Instituto Ethos também são bastante utilizados pelas organizações (Instituto Ethos, 2015).

De acordo com Campos e Melo (2008) quanto aos tipos de indicadores, ocorre uma confusão conceitual a respeito da distinção entre indicadores ambientais, indicadores de desenvolvimento sustentável/sustentabilidade e indicadores de desempenho ambiental. Indicadores ambientais traduzem dados relativos a determinado componente ou conjunto de componentes de um ou vários ecossistemas.

Já os indicadores de desenvolvimento sustentável/sustentabilidade compreendem informações relativas às várias dimensões da sustentabilidade: dimensões econômica, social, ambiental e institucional; e, por último, os indicadores de desempenho ambiental 
preocupam-se em refletir os efeitos sobre o meio ambiente dos processos e técnicas adotados para realizar as atividades de uma organização (Campos e Melo, 2008; Campos et al., 2015).

As empresas apresentam em seus relatórios ambientais, indicadores institucionais, incluindo aspectos relacionados a: número de colaboradores, número de pessoas atendidas pelos serviços prestados, colaboradores por sexo, porcentagem de mulheres, porcentagem de mulheres em cargo de chefia, número de colaboradores com necessidades especiais, número de analfabetos, colaboradores acima de 45 anos de idade, programas de treinamento e desenvolvimento de colaboradores, desempenho econômico-financeiro, entre outros. A Tabela 3 apresenta os principais indicadores institucionais mencionados nos relatórios ambientais destas empresas. 0 relatório ambiental do Grupo SOLVÍ é mais completo do que o Grupo ESTRE, considerando os indicadores institucionais.

Tabela 3. Principais indicadores institucionais das empresas SOLVÍ e ESTRE.

\begin{tabular}{|l|c|c|}
\hline \multirow{2}{*}{ Indicadores Institucionais } & \multicolumn{2}{|c|}{ Empresas } \\
\cline { 2 - 3 } & Grupo SOLVÍ & Grupo ESTRE \\
\hline Número de colaboradores & 19.000 & 13.300 \\
\hline Número de pessoas atendidas pelos serviços prestados & 11 milhões & 31 milhões \\
\hline Colaboradores por sexo & $\begin{array}{c}\text { Homem: } 81,75 \% \\
\text { Mulher: } 18,25 \%\end{array}$ & - \\
\hline Mulheres & $18,25 \%$ & $9 \%$ \\
\hline Mulheres em cargo de chefia & $22 \%$ & - \\
\hline Número de colaboradores com necessidades especiais & 334 & - \\
\hline Número de analfabetos & 21 & - \\
\hline Número de colaboradores acima de 45 anos & 7.069 & - \\
\hline Receita líquida (R\$) & 648 mil & 1.365 milhões \\
\hline
\end{tabular}

Fonte: Elaborado a partir do Relatório Socioambiental SOLVí (2018) e Relatório de Sustentabilidade ESTRE (2017).

A Tabela 4 mostra os principais indicadores de sustentabilidade das empresas. Destaca-se que o Grupo SOLVÍ em 2017, apresentou em seu relatório ambiental alguns indicadores específicos por empresa. Entretanto, no relatório ambiental de 2018, isto não foi mantido e vários indicadores deixaram de aparecer. Contatando-os a respeito disso, eles disseram que alguns indicadores deixaram de ser monitorados por decisão da diretoria.

Analisando a Tabela 4, verifica-se que muitos indicadores de sustentabilidade, na verdade referem-se a indicadores de monitoramento dos processos operacionais das empresas, por exemplo, toneladas de resíduos coletados, aterrados etc. Um indicador interessante que aparece é o consumo de água. A água é um recurso que aparece com predominância na gestão das empresas certificadas pela NBR ISO 14.001 (ABNT, 2004). 0 fato de a empresa ser certificada pela norma NBR ISO 14.001 constitui um diferencial no processo de gestão da água. A energia elétrica também é um recurso que aparece com predominância na gestão das empresas certificadas pela NBR ISO 14.001 (Souza et al. 2009; Machado Junior et al. 2013; Almeida e Sellitto, 2013).

Outros indicadores importantes, como consumo de energia elétrica e geração de resíduos sólidos, por exemplo não constam nos relatórios ambientais. Estas empresas acabam produzindo energia elétrica, a partir do biogás captado nos aterros sanitários ou dos próprios resíduos sólidos e o consumo energético interno é suprido por esta 
produção. Em relação aos resíduos sólidos, algumas empresas dos grupos apresentam sistemas internos de coleta seletiva e parceiros para fazer a reciclagem destes resíduos. Um conjunto adequado de indicadores de sustentabilidade exerce a função de advertir à comunidade sobre riscos e tendências do desenvolvimento, se constituindo como uma carta de navegação sobre o futuro, onde se vislumbra um destino, se acompanha o trajeto e se corrigem os rumos (Guimarães e Feichas, 2009; Scholl et al. 2015; Morioka et al. 2018).

Como aspecto positivo, é que todas as empresas apresentam indicadores de educação ambiental e indicadores de saúde, segurança e qualidade. O grupo SOLVí desenvolve alguns projetos de educação ambiental, como: o programa nossa vila limpa, que realiza ações de educação ambiental em locais que antes eram pontos viciados de descarte incorreto de resíduo urbano, destaca-se ainda o Portas Abertas, que recebe escolas em suas unidades operacionais e o Eco Escola, que desenvolve ações de educação ambiental nas escolas (SOLVÍ, 2018).

Tabela 4. Principais indicadores de sustentabilidade das empresas SOLVÍ e ESTRE.

\begin{tabular}{|c|c|c|c|c|c|c|}
\hline \multirow{3}{*}{$\begin{array}{l}\text { Indicadores de } \\
\text { sustentabilidade }\end{array}$} & \multicolumn{6}{|c|}{ Empresas } \\
\hline & \multicolumn{5}{|c|}{ Grupo SOLVÍ } & \multirow{2}{*}{$\begin{array}{c}\text { Grupo } \\
\text { ESTRE } \\
\text { Estre }\end{array}$} \\
\hline & $\begin{array}{l}\text { Solví } \\
\text { Holding }\end{array}$ & Koleta & Essencis & Organosolví & GRI & \\
\hline $\begin{array}{l}\text { Toneladas de resíduos } \\
\text { coletados }\end{array}$ & $\begin{array}{c}3,8 \\
\text { milhões }\end{array}$ & - & - & - & - & 8 milhões \\
\hline $\begin{array}{l}\text { Toneladas de resíduos } \\
\text { dispostos em aterros }\end{array}$ & $\begin{array}{c}11,2 \\
\text { milhões }\end{array}$ & - & - & - & - & $\begin{array}{c}6,1 \\
\text { milhões } \\
\end{array}$ \\
\hline $\begin{array}{l}\text { Emissões de metano evitadas } \\
\text { nos aterros (toneladas de } \mathrm{CO}_{2} \\
\text { eq.) }\end{array}$ & 2 milhões & - & - & - & - & 395 mil \\
\hline $\begin{array}{l}\text { Geração de energia elétrica a } \\
\text { partir do biogás (MWh) }\end{array}$ & 421.411 & - & - & - & - & 350.000 \\
\hline $\begin{array}{l}\text { Investimento em programas } \\
\text { sociais }\end{array}$ & $\begin{array}{c}2,7 \\
\text { milhões } \\
(\mathrm{R} \$)\end{array}$ & - & - & - & - & - \\
\hline $\begin{array}{l}\text { Consumo de água na } \\
\text { operação }\left(\mathrm{m}^{3}\right)\end{array}$ & - & $\begin{array}{c}7,04 \\
\text { mil } \\
\end{array}$ & - & - & - & - \\
\hline $\begin{array}{l}\text { Volume de percolado tratado } \\
\left(\mathrm{m}^{3}\right)\end{array}$ & - & - & 818 mil & - & - & $\begin{array}{c}1,2 \\
\text { milhões }\end{array}$ \\
\hline $\begin{array}{l}\text { Valorização energética de } \\
\text { resíduos }(\mathrm{t})\end{array}$ & - & - & $\begin{array}{c}2,8 \\
\text { milhões } \\
\end{array}$ & - & - & $45 \mathrm{mil}$ \\
\hline Compostagem $(\mathrm{t})$ & - & - & - & $\begin{array}{l}23 \\
\text { mil }\end{array}$ & - & - \\
\hline $\begin{array}{l}\text { Toneladas de resíduos } \\
\text { reciclados }(\mathrm{t})\end{array}$ & - & - & - & - & $\begin{array}{r}875 \\
\text { mil } \\
\end{array}$ & 95 mil \\
\hline $\begin{array}{l}\text { Indicadores de } \\
\text { biodiversidade }\end{array}$ & Não & Não & Sim & Não & Não & Não \\
\hline $\begin{array}{l}\text { Indicadores de saúde, } \\
\text { segurança e qualidade }\end{array}$ & Sim & Sim & Sim & Sim & Sim & Sim \\
\hline $\begin{array}{l}\text { Indicadores de educação } \\
\text { ambiental }\end{array}$ & Sim & Sim & Sim & Sim & Sim & Sim \\
\hline
\end{tabular}

Fonte: Elaborado a partir dos Relatórios Socioambientais SOLVÍ (2017) e SOLVÍ (2018) e Relatórios de Sustentabilidade ESTRE (2016) e ESTRE (2017). 
Aspectos que reforçam o desempenho ambiental e social dessas organizações. De acordo com Nogueira e Capaz (2014, p. 235) a avaliação de desempenho ambiental, é uma ferramenta para mensuração da eficácia de procedimentos adotados por uma organização, em relação a conservação ambiental ou otimização de recursos naturais. A norma ABNT NBR ISO 14.031:2004, apresenta uma série de exemplos de indicadores, que podem ser adotados na avaliação de desempenho ambiental (ABNT, 2019). Esta norma sugere o uso de indicadores, que basicamente fornece informação sobre o desempenho ambiental da organização. A norma ISO 14.031:2004 para avaliação de desempenho ambiental é uma das mais utilizadas pelas organizações, porém se pode citar pelo menos outras duas ferramentas importantes: a cartilha "Indicadores de Desempenho Ambiental da Indústria (FIESP, 2004) e o método Pegada Ecológica (Ecological Footprint Method) proposto por Wackernagel e Rees (1996).

O grupo ESTRE criou seu Instituto, que é responsável pelas ações na sociedade de responsabilidade socioambiental. Seu programa de educação ambiental atendeu em 2017, 47 mil pessoas em 57 cidades, destacando-se os seguintes programas: Oficinas Pedagógicas: "Cadê o lixo que estava aqui?", Escolas Sustentáveis e Histórias para Pertencer ao Mundo, todos estes programas trabalham a educação ambiental em diferentes espaços, capacitando jovens e adultos em geral (ESTRE, 2017). Estes programas de educação ambiental apresentam vários indicadores, como: número de visitantes, número de palestras, número de capacitações etc. Outro destaque são as ações sociais realizadas por estas empresas, incluindo mobilizações de voluntariado, incentivo à cultura, com apoio a peças teatrais, publicações de livros e cinema e várias intervenções nas comunidades de entorno.

A Essencis empresa do grupo SOLVí foi a única que apresentou indicador de biodiversidade. No ano de 2017, no relatório ambiental da empresa constava a ocorrência de 123 espécies de aves, 10 de mamíferos e 126 árvores nativas (ESSENCIS, 2017). Porém, a partir de 2018, estes indicadores deixaram de existir. Neste mesmo relatório, consta em sua unidade operacional, no Município de Caieiras-SP, uma área verde conservada de aproximadamente 150 ha e um viveiro de mudas, que dá apoio também ao programa de educação ambiental. No relatório ainda existe alguns benefícios econômicos e sociais ao município de Caieiras, como: pagamento de 12 milhões de $\mathrm{R}$ /ano de Imposto sobre Serviço (ISS), R\$ 3 milhões/ano de Fundo Social e R \$ 6 milhões/ano referente à coleta e à destinação de resíduos sólidos urbanos do município, ou seja, 100\% do resíduo urbano da cidade é coletado e destinado gratuitamente.

A Norma ABNT NBR ISO 14.001:2015 - Sistemas de gestão ambiental (SGA) Requisitos com orientações para uso, especifica critérios que uma organização pode usar para aumentar seu desempenho ambiental. Um requisito obrigatório do SGA é a política ambiental, ou seja, a organização formula uma intenção e direção frente ao seu desempenho ambiental, formalmente expresso. Todas as empresas estudadas apresentaram suas políticas ambientais, atendendo este requisito da norma. No âmbito da norma, o desempenho se aplica a um resultado mensurável, relacionado a constatações qualitativas ou quantitativas. Especificamente desempenho ambiental, se dá através da gestão dos aspectos e impactos ambientais da organização, medidos por meio de indicadores, neste caso, indicadores de sustentabilidade, que podem ser medidos, monitorados, acompanhados etc. A melhoria contínua de uma atividade, processo, produto, serviço, sistema ou organização, recorre ao aumento de desempenho como um todo.

Em termos da norma ISO 14.001, o requisito 9 determina a avaliação de desempenho, em que a organização deve monitorar, medir, analisar e avaliar seu desempenho ambiental. A organização deve determinar os critérios pelos quais esta empresa deverá avaliar seu desempenho ambiental e indicadores apropriados. A organização também deve comunicar as informações pertinentes sobre seu desempenho 
ambiental. Neste aspecto, somente as empresas dos grupos SOLVÍ e ESTRE, comunicam seus desempenhos ambientais por meio da publicação anual dos seus relatórios ambientais e neles seus indicadores de sustentabilidade selecionados para analisar o desempenho e eficácia dos seus sistemas de gestão ambiental.

A norma ISO 14.001 apresenta alguns exemplos de temas ambientais/indicadores que podem ser pertinentes para o contexto de uma organização, incluindo: qualidade do ar, qualidade da água, uso do solo, disponibilidade de matérias-primas e recursos naturais, uso de energia, geração de resíduos, reciclagem e biodiversidade. Nota-se, que alguns destes temas ambientais mencionados foram incorporados na forma de indicadores de sustentabilidade pelas empresas estudadas. A norma ABNT ISO 14.031:2004 - Gestão ambiental - Avaliação de desempenho ambiental - Diretrizes, fornece orientação para o uso da avaliação de desempenho ambiental por uma organização. De acordo com esta norma, a avaliação de desempenho ambiental é um processo para facilitar as decisões gerenciais com relação ao desempenho ambiental de uma organização e que compreende a seleção de indicadores de sustentabilidade, que fornece informações desta organização. Os indicadores são informações de ordem institucional, gerencial, operacional e ambiental de uma determinada organização.

A norma apresenta inúmeras sugestões de indicadores de análise de desempenho ambiental (ADA), considerando inclusive as questões e visões das partes interessadas. Alguns indicadores importantes são: resíduos (quantidade de resíduos/ano, etc.), emissões atmosféricas (quantidade de emissões com potencial de destruição da camada de ozônio, potencial de mudança global, etc.), efluentes para a água e solo, qualidade de recursos hídricos, espécies ameaçadas, questões relacionadas ao ar, água e solo, flora, fauna, aspectos humanos (condição de uma determinada população), estética, patrimônio e cultura, ou seja, grupos de indicadores socioeconômicos, etc.

Embora as empresas estudadas não tenham implantado em seus sistemas de gestão a ISO 14.031, alguns dos indicadores desta norma se fazem presentes em seus relatórios ambientais. Além destas normas ISO é possível verificar a existência de outras metodologias e instituições que apresentam sistemas com indicadores de sustentabilidade. Será analisado sequencialmente os procedimentos GRI e Instituto Ethos.

A metodologia GRI estabelece algumas diretrizes que incluem indicadores econômicos, ambientais, sociais e organizacionais. Os indicadores de sustentabilidade abrangem o desempenho relacionado a insumos (como material, energia e água) e a produção (emissões, efluentes e resíduos). Além disso, abarcam o desempenho relativo à biodiversidade, à conformidade ambiental e outras informações relevantes, tais como investimentos e gastos com meio ambiente e os impactos de produtos e serviços (GRI, 2013).

Alguns destes temas, como por exemplo: água, emissões, efluentes e biodiversidade foram alguns dos indicadores identificados nas empresas estudadas. Particularmente, descobrimos que a empresa SOLVÍ utiliza a metodologia GRI como base de análise de seu desempenho ambiental, portanto esperava-se, que efetivamente houvesse concordância em relação ao uso de indicadores. Esta metodologia apresenta um conjunto bastante robusto de protocolos de indicadores. Portanto, seguir estas diretrizes da metodologia, certamente proporciona uma gestão de excelência a uma organização.

No contexto ambiental são mensurados muitos indicadores de desempenho ambiental, sendo possível mensurar: consumo de materiais, energia, água, impactos sobre a biodiversidade, geração de emissões, efluentes e resíduos (GRI, 2013). Embora tenha sido possível identificar alguns indicadores de sustentabilidade desta natureza implementados nos sistemas de gestão das empresas avaliadas, nota-se efetivamente que tal uso ainda é bastante incipiente, apresentando possibilidades de se estabelecer dentro destas organizações uma infinidade maior de indicadores, tornando seus sistemas de análise de desempenho mais complexos e robustos. 
O Instituto Ethos apresenta um conjunto de indicadores para negócios sustentáveis e responsáveis. Esta ferramenta de gestão dá apoio as empresas no sentido de incorporação da sustentabilidade e responsabilidade social empresarial em suas estratégias de negócios. Tal aplicação se dá no âmbito de várias dimensões da gestão empresarial, principalmente visão e estratégia e governança e gestão, que envolvem código de conduta, compromissos voluntários, sistemas anticorrupção etc. Foi possível verificar no sistema de gestão das empresas SOLVÍ e ESTRE estas dimensões, o que reforça a importância empresarial destas práticas, sobretudo na imagem empresarial. Mas, as dimensões social e ambiental também fazem parte do conjunto dessas ações. Aspectos relacionados ao direito humano, relações trabalhistas, saúde e segurança no trabalho, qualidade de vida, direito do consumidor, consumo consciente e envolvimento com a comunidade são práticas fundamentais no contexto dos indicadores Instituto Ethos (2015). A temática meio ambiente também se faz presente nestas práticas, caracterizandose por subtemas, como: mudanças climáticas, gestão e monitoramento dos impactos sobre os serviços ecossistêmicos e a biodiversidade, uso sustentável de recursos naturais (materiais, água, energia, biodiversidade, restauração de habitats, educação e conscientização ambiental), também impactos do consumo, transporte, logística, distribuição e logística reversa, etapas do processo produtivo, incorporados na análise de ciclo de vida (ACV) do produto.

Alguns indicadores pontuais desta relação foram observados nas empresas avaliadas, mas não foi encontrado nestas empresas nenhuma análise de ciclo de vida, que demandaria por parte da organização uma análise mais profunda do seu processo produtivo como um todo. Em uma avaliação mais detalhada dos indicadores de sustentabilidade do Instituto Ethos, é possível verificar a existência de vários indicadores quantitativos interessantes, como: valor total de redução de emissões de gases de efeito estufa, número de reclamações sobre os impactos ambientais, número de vazamentos, emissões atmosféricas, consumo de recursos e materiais, consumo de água, energia, resíduos recuperados ou reciclados, etc. Ou seja, uma lista enorme de indicadores, que ajudam na análise do desempenho ambiental de uma organização (Instituto Ethos, 2015).

Indicadores de resíduos reciclados foram observados nas duas empresas estudadas, principalmente porque são organizações do setor de resíduos e acabam incorporando estas práticas automaticamente em seus sistemas de gestão.

Em síntese, foi possível observar nas empresas estudadas a utilização de muitos indicadores de sustentabilidade. 0 grupo SOLVí apesar de incorporar em seu sistema de gestão vários indicadores presentes na metodologia GRI e Instituto Ethos, não se baseia em um conjunto único de indicadores de uma determinada instituição. Entretanto, o grupo ESTRE aplica em seu sistema de gestão as práticas de reporte da metodologia GRI.

A existência, embora pouca, de empresas do setor de resíduos sólidos fazendo uso de indicadores é um aspecto muito positivo. A adesão desse setor produtivo aos sistemas de gestão é algo bem recente e, é de se esperar evidentemente que este processo se encontre em um momento de adequação e aperfeiçoamento. Mas, ainda assim é um aspecto favorável, quando estas organizações buscam melhorar seus processos produtivos, sistemas de gestão ambiental, responsabilidade social e compromissos com a sociedade.

Nota-se ainda que as empresas do setor de resíduos sólidos, apesar do uso dos indicadores de sustentabilidade, não apresentam uma análise mais profunda dos impactos destes na sociedade, limitando-se a apenas expor seus resultados superficialmente. Poucos indicadores são apresentados no formato ano a ano, o que dificulta bastante uma avaliação mais detalhada das informações.

Analisando somente o pilar ambiental e alguns indicadores disponíveis nos relatórios ambientais, evidencia-se que não é uma tarefa muito simples avaliar o desempenho ambiental destas organizações. Tomando como exemplo, o indicador 
consumo de água e energia, observa-se que no grupo SOLVÍ em 2017, foi maior do que em anos anteriores (2015 e 2016), por outro lado, as emissões de gases foram menores em 2017 comparado com estes outros anos e também aumentou a valorização energética de resíduos para o mesmo período, ou seja, 4 indicadores, dois foram negativos, mas outros dois foram positivos. E na verdade, somente estes quatro indicadores efetivamente contribuem para uma análise no contexto de desempenho ambiental. Analisar dentro deste contexto, o grupo ESTRE torna-se ainda mais difícil, pois em seu relatório ambiental atual - 2017, aparece somente os resultados referente ao próprio ano.

Campos et al. (2015) estudando várias empresas do setor de papel/celulose, moveleiro/madeira, têxtil e de serviços, para determinar o conjunto de indicadores de desempenho ambiental que estas empresas com ISO 14.001 se utilizavam, relataram que a grande maioria apresenta indicadores de desempenho ambiental, atendendo os requisitos legais, metas e objetivos ambientais etc. Destaque para as empresas dos setores de papel/celulose e moveleiro e madeira. Esta tendência pode ser atribuída ao fato de que esses setores foram pioneiros buscando certificar seu sistema de gestão ambiental. As empresas nos setores de serviços, por exemplo, são os menos propensos a usar indicadores, provavelmente porque suas características são menos poluentes. Comoglio e Botta (2012) comentam que a questão fundamental é que a ISO 14.001 não exige que as empresas atinjam níveis mínimos de desempenho (além do cumprimento legal) e nem fornece métodos para medir melhoria contínua. Vários aspectos ambientais são monitorados no sistema de gestão ambiental por meio de muitos indicadores, mas, os mais detalhados referem-se principalmente a melhoria de desempenho econômico e financeiro e em relação aos ambientais, destacam-se aqueles relacionados a tentativa de redução de custos, envolvendo gerenciamento de resíduos e uso de recursos naturais.

A SOLVÍ é a única empresa do setor de resíduos sólidos no estado de São Paulo, que disponibiliza prontamente em seu site os relatórios ambientais desde ano de 2006. Portanto, muito provavelmente, é a empresa mais amadurecida do setor de resíduos, no tocante a gestão empresarial como um todo.

0 modelo de gestão e o padrão do relatório sociambiental da SOLVí nos parece mais adequado e interessante, todavia mesmo este ainda poderia ser aperfeiçoado, com a inserção de outros indicadores de sustentabilidade e avaliações mais detalhadas destes resultados em geral. Um aspecto importante para análise de desempenho é a realização das auditorias, neste caso, todas as empresas avaliadas as realizaram. As auditorias são imprescindíveis, já que atendem aos requisitos das normas, mas também contribui no processo de melhoria contínua dos sistemas de gestão como um todo.

\section{Conclusões}

Em síntese, a implantação por uma organização de um sistema de gestão ambiental contribui para melhorar, controlar e aperfeiçoar suas atividades e processos, potencializando a redução de impactos ambientais. As empresas do setor de resíduos certificadas pela Norma ISO 14.001 do Estado de São Paulo estão se adequando e aperfeiçoando quanto ao uso de indicadores de sustentabilidade. Destacam-se no setor as organizações SOLVÍ e ESTRE. Estas apresentam seus indicadores de sustentabilidade em suas publicações anuais (Relatórios de Sustentabilidade). A SOLVí aparentemente nos pareceu mais amadurecida em relação ao uso dos indicadores de sustentabilidade, pois já publica seus relatórios desde 2006.

Uma análise mais profunda dos indicadores de sustentabilidade em consonância a avaliação de desempenho ambiental, não foi possível ser realizado, primeiro pela indisponibilidade de informações pelo menos do setor de resíduos sólidos, somente em duas empresas efetivamente foi possível coletar dados e somente uma, a SOLVÍ apresenta 
um conjunto histórico maior de informações, mas demandaria mais tempo para realizar esta avaliação mais detalhada.

Entretanto, foi possível identificar os indicadores de sustentabilidade utilizados pelas empresas do setor e evidenciar que alguns destes estão presentes ou são de alguma forma sugeridos nas Normas ISO 14.001 e 14.031, metodologia GRI e Instituto Ethos.

As organizações do setor de resíduos sólidos poderiam usar muito mais os indicadores de sustentabilidade mencionados na ISO 14.031 - norma de desempenho ambiental, que apresenta um conjunto de indicadores consistentes, contribuindo para 0 aperfeiçoamento e melhoria contínua dos sistemas de gestão dessas empresas.

0 uso de indicadores de sustentabilidade no contexto empresarial é uma prática, que efetivamente permite minimizar impactos causados pelos processos produtivos e podem indicar um amadurecimento das questões socioambientais empresariais na direção de uma gestão de excelência e, sobretudo, sustentável.

\section{Conflito de interesses}

Os autores declaram não haver conflito de interesses.

\section{Referências}

ABNT - Associação Brasileira de Normas Técnicas. Certificação de sistemas de gestão. Rio de Janeiro: ABNT, 2004.

ABNT - Associação Brasileira de Normas Técnicas. NBR ISO 14.001:2004: Sistema de Gestão Ambiental. Rio de Janeiro: ABNT, 2004.

ABNT - Associação Brasileira de Normas Técnicas. NBR ISO 14.031:2004: Gestão ambiental - Avaliação de desempenho ambiental. Rio de Janeiro: ABNT, 2004.

Abrantes, J. Gestão da qualidade. Rio de Janeiro: Interciência, 2009.

Almeida, T. S. M.; Sellitto, M. A. Avaliação do desempenho ambiental de uma instituição pública de ensino técnico e superior. Produção, v. 23, n. 3, p.625-636, 2013. https://doi.org/10.1590/S0103-65132012005000090

BANAS. ISO 14.001. 2019. Disponível em: <https://www.banasqualidade.com.br/>. Acesso em: 10 maio 2019.

Barbieri, J. C. Gestão ambiental empresarial: conceitos, modelos e instrumentos. 3. ed. atual. e ampl. São Paulo: Saraiva, 2011.

Campos, L. M. S.; Heizen, D. A. M.; Verdinelli, M. A.; Miguel, P. A. C. Environmental performance indicators: A study on ISO 14001 certified companies. Journal of Cleaner Production, v. 99, p. 286-296, 2015. https://doi.org/10.1016/j.jclepro.2015.03.019

Campos, L. M. S.; Melo, D. A. Indicadores de desempenho dos Sistemas de Gestão Ambiental (SGA): uma pesquisa teórica. Produção, v. 18, p. 540-555, 2008. https://doi.org/10.1590/S0103-65132008000300010

Campos, L. M. S.; Sehnem, S.; Oliveira, M. A. S.; Rossetto, A. M.; Coelho, A. L. A. L.; Dalfovo, M. S. Relatório de sustentabilidade: perfil das organizações brasileiras e estrangeiras segundo o padrão da Global Reporting Initiative. Gestão \& Produção, v. 20, p. 913-926, 2013. https://doi.org/10.1590/S0104-530X2013005000013

Comoglio, C.; Botta, S. The use of indicators and the role of environmental management systems for environmental performances improvement: A survey on ISO 14001 certified

Rev. Bras. Gest. Amb. Sustent., 2021, vol. 8, n. 18, p. 3-19. 
companies in the automotive sector. Journal of Cleaner Production, v. 20, p. 92-102, 2012. https://doi.org/10.1016/j.jclepro.2011.08.022

Damian, T. Gestão de empresa: tópicos especiais em gestão empresarial. Jundiaí: Paco Editorial, 2015.

Dongab, Y.; Hauschilda, M. Z. Indicators for environmental sustainability. Anais do 24th CIRP Conference on Life Cycle Engineering, Procedia CIRP 61, 2017.

ESSENCIS. Balanço socioambiental. 2017. Disponível em: $<$ https://www.essencis.com.br>. Acesso em: 23 maio 2018.

ESTRE. Relatório de sustentabilidade. 2016. Disponível em: <http://www.estre.com.br>. Acesso em: 13 maio 2018.

ESTRE. Relatório de sustentabilidade. 2017. Disponível em: <http://www.estre.com.br>. Acesso em: 23 maio 2018.

FIESP - Federação das Indústrias do Estado de São Paulo. Indicadores de desempenho ambiental na indústria - 2004. São Paulo: FIESP/CIESP, 2004. Disponível em: $<$ https://www.fiesp.com.br/indices-pesquisas-e-publicacoes/indicadores-dedesempenho-ambiental-da-industria-2004/>. Acesso em: 12 fev. 2019.

FIRJAN - Federação das Indústrias do Estado do Rio de Janeiro. Manual de indicadores ambientais. Rio de Janeiro: DIM/GTM, 2018.

Fogliatti, M. C. Sistema de gestão para empresas. 2. ed. Rio de Janeiro: Interciência, 2011.

Gil, A. C. Como elaborar projetos de pesquisa. 4. ed. São Paulo: Atlas, 2007.

GRI - Global Reporting Initiative. About GRI. 2013. Disponível em: <http://www.globalreporting.org/>. Acesso em: 23 maio 2017.

Guimarães, R. P.; Feichas, S. A. Q. Desafios na construção de indicadores de sustentabilidade. Ambiente \& Sociedade, v. 12, p. 307-323, 2009.

IBGE - Instituto Brasileiro de Geografia e Estatística. Indicadores de desenvolvimento sustentável: Brasil 2004. Rio de Janeiro: IBGE, 2004.

INMETRO - Instituto Nacional de Metrologia, Qualidade e Tecnologia. Certifiq - Sistema de Gerenciamento de Certificados. Brasília: INMETRO, 2019. Disponível em: $<$ https://certifiq.inmetro.gov.br/>. Acesso em: 10 mar. 2019.

Instituto Ethos. Indicadores Ethos de Responsabilidade Social Empresarial. 2015. Disponível em: <https://www.ethos.org.br/conteudo/indicadores/>. Acesso em: 25 maio 2019.

Machado Junior, C.; Mazzali, L.; Souza, M. T. S.; Furlaneto, C. J.; Prearo, L. C. A gestão dos recursos naturais nas organizações certificadas pela norma NBR ISO 14001. Produção, v. 23, n. 1, p. 41-51, 2013. https://doi.org/10.1590/S0103-65132012005000005

Morioka, S. N.; Carvalho, M. M. Discutindo sustentabilidade no contexto de negócios e em relatórios de desempenho: análise de estudos de caso brasileiros. Gestão \& Produção, v. 24, n. 3, p. 514-525, 2017. https://doi.org/10.1590/0104-530x2665-16

Morioka, S. N.; Iritani, D. R.; Ometto, A. R.; Carvalho, M. M. Revisão sistemática da literatura sobre medição de desempenho de sustentabilidade corporativa: uma discussão sobre contribuições e lacunas. Gestão \& Produção, v. 25, n. 2, p. 284-303, 2018. https://doi.org/10.1590/0104-530x2720-18 
Nogueira, L. H. A.; Capaz, R. S. Ciências Ambientais para Engenharia. 1. ed. Rio de Janeiro: Elsevier, 2014.

Pereira, J. A. A.; Borges, L. A. C.; Barbosa, A. C. C.; Borém, R. A. T. Fundamentos da avaliação de impactos ambientais com estudo de caso. Lavras: UFLA, 2014.

PNIA - Painel Nacional de Indicadores Ambientais. Proposta preliminar do PNIA 2012. Brasília: Ministério do Meio Ambiente, 2012. Disponível em: <http://www.mma.gov.br/pnia/>. Acesso em: 23 maio 2017.

Ribeiro Neto, J. B. M.; Tavares, J. C.; Hoffmann, S. C. Sistemas de gestão integrados: qualidade, meio ambiente, responsabilidade social e segurança e saúde no trabalho. 5. ed. São Paulo: Editora Senac, 2017.

Sánchez, L. E. Avaliação de impacto ambiental: conceitos e métodos. 2. ed. São Paulo: Oficina de Textos, 2013.

Santiago, L. S.; Dias, S. M. F. Matriz de indicadores de sustentabilidade para a gestão de resíduos sólidos urbanos. Engenharia Sanitária e Ambiental, v. 17, n. 2, p. 203-212, 2012. https://doi.org/10.1590/S1413-41522012000200010

Scholl, C. A.; Hourneaux Junior, F.; Galleli, B. Sustentabilidade organizacional: aplicação de índice composto em uma empresa do setor químico. Gestão \& Produção, v. 22, n. 4, p. 695-710, 2015. https://doi.org/10.1590/0104-530X1343-13

SGS. ISO 9.001. 2019. Disponível em: <https://www.sgsgroup.com.br/>. Acesso em: 15 maio 2019.

SOLVÍ. Relatório Socioambiental - 2017. 2017. Disponível em: <https://www.solvi.com>. Acesso em: 23 maio 2018.

SOLVÍ. Relatório Socioambiental - 2018. 2018. Disponível em: <https://www.solvi.com>. Acesso em: 23 de abr. 2019.

Souza, J. H.; Paulella, E. D.; Tachizawa, T.; Pozo, H. Desenvolvimento de indicadores síntese para o desempenho ambiental. Saúde e Sociedade, v. 18, n. 3, p. 500-514, 2009. https://doi.org/10.1590/S0104-12902009000300014

Souza, L. D.; Valadão Júnior, V. M.; Medeiros, C. R. O. Crime corporativo e o discurso da responsabilidade socioambiental: inconsistências, contradições e indiferença no diálogo da corporação com stakeholders. Gestão \& Produção, v. 24, n. 4, p. 690-703, 2017. https://doi.org/10.1590/0104-530x1394-17

Takashina, N. T. Indicadores da qualidade e do desempenho. Rio de Janeiro: Qualitymark, 1999.

Van Bellen, H. M. Desenvolvimento sustentável: uma descrição das principais ferramentas de avaliação. Ambiente \& Sociedade, v. 7, $\quad$ n. 1, p. 1-22, 2004. https://doi.org/10.1590/S1414-753X2004000100005

Van Bellen, H. M. Indicadores de sustentabilidade: uma análise comparativa. 2. ed. Rio Janeiro: Editora FGV, 2006.

Wackernagel, M.; Rees, W. E. Our ecological footprint: Reducing impact on the Earth. Gabriola Island, Canada: New Society, 1996.

Informação da Licença: Este é um artigo Open Access distribuído sob os termos da Licença Creative Commons Attribution, que permite uso irrestrito, distribuição e reprodução em qualquer meio, desde que a obra original seja devidamente citada. 